\title{
CRÍTICA DEL SUBJETIVISMO EN ESTIMATIVA JURÍDICA
}

sumario: 1. Planteamiento rigoroso del problema. 2. Diversas presentaciones del escepticismo axiológico, especialmente en materia jurídica. 3. Cuál es la cuestión aquí analizada: razón y valores. 4. Algunas objeciones críticas frente al neo-positivismo. 5. E] positivismo juridico fomenta la conformidad con todas las atrocidades.

\section{Planteamiento rigoroso del problema}

Las controversias entre subjetivismo (equivalente a escepticismo) axiológico, por una parte, y, por otra, objetivismo estimativo parecen turbias, por causa de varios factores, los cuales producen muchas confusiones.

Ante todo, tropezamos a veces con una terminología infortunada. Al subjetivismo estimativo o axiológico -que desemboca en una posición escéptica- se le denomina, no sólo algunas veces sino muy frecuentemente, "relativismo axiológico". Y se le denomina así, no sólo por quienes sostienen esa postura, sino también por quienes la objetan críticamente.

Entiendo que esa denominación "relativismo" es superlativamente infortunada y que constituye la fuente de graves equívocos. Considero que se debe insistir enfáticamente sobre el punto de que, incluso profesando un acendrado objetivismo estimativo, se ha de reconocer que en los juicios de valor hay muchos factores contingentes y muchas dependencias relativas a las circumstancias de los hechos de cada realidad humana concreta, sea individual o sea social, y, por lo tanto, relativas también a condiciones de situación histórica, de época y de lugar. Por lo tanto, el objetivismo axiológico no sólo admite y reconoce, sino que subraya enérgicamente esas dimensiones de relatividad de los juicios de valor.

Parece obvio que los juicios concretos de valor son relativos, deben ser relativos, es más, tienen que ser relativos, a las realidades valoradas, con todas las características particulares que tales realidades presentan. En el caso de estimaciones jurídicas, estas estimaciones son habitualmente, y deben ser, relativas a las realidades sociales que se trate de ordenar, a los tipos de conflictos de intereses que se intente resolver; relativas por consiguiente también a las circunstancias particulares de situación históriça de época y de lugar; relativas a los valores que sean reputados como supremos; relativas a los fines que se haya querido establecer; y relativas, por lo tanto, al punto de vista que se adopte.

Ahora bien, el reconocimiento de todas esas dependencias relacionales 
no implica de ninguna manera necesariamente la carencia de una base objetivamente válida que legitime esas estimaciones.

La elección del punto de vista, así como el reconocimiento de las dependencias relacionales, son posiciones que deben ser legitimadas o fundamentadas objetivamente; objetivamente, en cuanto a la elección del punto de vista mejor y además pertinente; así como legitimadas objetivamente en cuanto al reconocimiento de las dependencias relacionales.

Lo que el objetivismo axiológico sostiene, y por eso es objetivismo, es que la raíz o primer cimiento o criterio básico de los juicios de valor constituye un a priori con validez objetiva, esto es, necesaria. Pero en los juicios de valor no figura solamente esa primaria raíz a priori, antes bien, los juicios de valor tienen componentes contingentes, empíricos, relativos a situaciones de hecho. ${ }^{1}$ Un juicio de valor emplea su raíz o inspiración objetivamente válida en la ordenación de unas realidades contingentes de hecho, muy diversas de otras realidades humanas, y que además están sujetas a múltiples procesos de cambio.

Por eso, es no sólo perfectamente compatible, sino necesariamente armonizable el criterio de objetividad, de nècesaria validez, de la inspiración estimativa, con las demandas concretas, singulares, contingentes, relativas, de las realidades humanas que deben ser ordenadas o cuyos problemas prácticos de conducta deben ser resueltos.

Por consiguiente, llamar "relativismo" a la postura de nihilista escepticismo es un desdichado equívoco que engendra múltiples confusiones funestas. Así pues, propongo eliminar este vocablo "relativismo" para la designación del subjetivismo escéptico. $Y$ sugiero denominar éste precisamente con tal término, "subjetivismo" o, si se quiere, también como "psicologismo".

Otra fuente de confusiones es el hecho de que muchos subjetivistas fabrican para su uso particular, como blanco de sus objeciones, una muy peculiar y arbitraria imagen del objetivismo. Algunos subjetivistas suponen que el objetivismo es equivalente a la tesis de que hay una especie de código moral y una especie de código jurídico ideales, repletos de contenido, de normas materiales, códigos en los cuales todo problema de conducta estaría previsto y resuelto de una vez y para siempre, con validez necesaria y universal, es decir, con validez absoluta. Ahora bien, una tal confusión -que sería modelo del más insensato utopismo y ucronismo- no resiste el embate de una crítica elemental. Si el objetivismo axiológico fuera eso, entonces podríamos echarlo definitivamente por la borda, ya que constituiría un dislate frenético.

El objetivismo no sostiene que en los juicios de valor todos sus componentes tengan una validez necesaria y objetiva. De ninguna manera. Por el

1 Véase Luis Recaséns Siches, Tratado general de filosofia del derecho, $4^{\mathrm{a}}$ ed., Editorial Porrúa, México, 197o, pp. $400-420$. 
contrario, el objetivismo reconoce que en los juicios de valor -morales, políticos, jurídicos, etc.-, hay muchos componentes empíricos, componentes de facto, que dependen de múltiples circunstancias contingentes y variables. Circunstancias relativas a los materiales humanos efectivos con los cuales, en los cuales y para los cuales se tiene que operar; es decir, diversas y cambiantes realidades humanas particulares. Y puesto que los juicios de valor dan origen a los modos según los cuales esas realidades humanas deben ser tratadas y ordenadas, es obvio que la condición fáctica de tales realidades habrá de influir en gran medida sobre esos modos. Tales circunstancias comprenden dependencias de cómo sea la realidad humana que venga en cuestión; dependencias en que esa realidad humana está de sus componentes concretos, y de la situación histórica; situación histórica que, a su vez, depende de factores de cuál sea la época en la que se viva; y también de cuál sea el lugar en el que hayan surgido los problemas de ordenación de la conducta práctica, que tiene uno ante sí.

Así pues, muy correctamente se puede decir que, relativamente a todos los factores concretos y singulares circunstantes, no sólo se puede sino que se debe emitir juicios diferentes de valor; y que cuando las circunstancias se transforman, deben cambiar también los juicios de valor. Pero, en cambio, se sostiene que la razón por la cual se emite cada uno de esos juicios de valor - diferentes y mudables- es la misma; y que esa razón tiene una validez objetiva.

La condicionalidad de los juicios de valor a los ingredientes de las situaciones humanas y de las circunstancias de éstas entrañan una relatividad perfectamente justificada. Pero esa relatividad no es en modo alguno equivalente a fortuito subjetivismo escéptico.

Sucede que muchos autosedicentes relativistas en el fondo son radicales subjetivistas y, por consiguiente, escépticos, ciegos voluntarios para la intuición de los valores fundamentales y pertinentes. Y, a título de relativistas extienden irresponsablemente su relativismo de manera universal, no sólo a las dependencias relacionales, sino a la elección de los puntos de vista que puedan en principio ser adoptados. $Y$ de tal guisa, tales relativistas universales caen en un total escepticismo axiológico.

Cierto que según adoptemos el punto de vista del microbio patógeno o el punto de vista del ser humano, la enfermedad infecciosa resultará valiosa o antivaliosa: valiosa para el microbio que se desenvuelve y prospera; antivaliosa para la persona que sufre la dolencia infecciosa. Según que adoptemos el punto de vista de una chimpancé o el punto de vista humano, Darwin resultará respectivamente superior o inferior a un simio antropoide. La mona puede probablemente, seguramente, preferir que su compañero sea un mono y no el señor Darwin. Concedamos, desde luego, a esa mona el privilegio de elegir de acuerdo con sus pautas simiescas; pero en todo caso, replicaremos 
que en la situación presente de los asuntos humanos debemos ineludible y necesariamente, con objetiva validez, reconocer a Darwin un rango superior al del chimpancé. ${ }^{2}$

Desde el punto de vista de la apología de la demagogia y del crimen al por mayor, Hitler puede ser considerado como bueno, como buen demagogo, como perfecto criminal; mientras que, desde el punto de vista de los valones humanos, particularmente de los valores morales, políticos y jurídicos, nos aparecerá como detestable. ${ }^{3}$

A la luz de los ejemplos expuestos, resulta evidente el error de extender la relatividad o relacionalidad de los juicios estimativos a la elección de los puntos de vista y de los supremos criterios rectores.

A este respecto, Edmond Cahn dice que ya es hora de que el relativismo universal adquiera una medida suficiente de autoconciencia y de reflexión funcional.4 Si se nos asegura que todo depende del punto de vista y que todo cambia de acuerdo con las variaciones de éste, entonces la elección del punto de vista, del ángulo de visión, de la perspectiva, se convierte en el problema candente y central de la axiología, cuya resolución implica la más importante responsabilidad humana. Si todo depende del punto de vista, entonces necesitamos perentoriamente elegir el punto de vista que sea el mejor, más sabio, más ilustrado, más prudente, el mejor entre todos los puntos de vista posibles. Si todo depende del punto de vista, entonces la filosofía moral y la filosofía jurídica deben, ante todo, examinar los diversos puntos de vista posibles, contrastar sus respectivos supuestos, sus respectivas implicaciones y sus respectivas consecuencias de acuerdo con unos criterios supremos, e indicar el punto de vista más digno de estima. Y ciertamente hay esos criterios supremos, por ejemplo: dignidad de la persona humana; libertades individuales que fluyen como corolarios de la idea de la dignidad; sociedad democrática; bienestar general.

$Y$ si se pretende frívola e-irresponsablemente universalizar el subjetivismo en la elección de los puntos de vista, entonces se abre de par en par una ancha puerta a cualquier propósito de deshumanización del hombre, lo cual equivale a la bestialización del ser humano. "Sucede, sin embargo, que la inmensa mayoría de esos subjetivistas universales son personas civilizadas, honestas, justas, decentes, quienes, a pesar de sus devaneos relativistas, no consentirian ningún intento de ser integralmente animalizadas. Su subjetivismo

2 Edmond Cahn, The Edmond Cahn Reader: Confronting Injustice, Edited by Leonore L. Cahn, Foreword by Hugo Black, Associate Justice, U. S. Supreme Court. General Introduction and Prefatory Chapter and Notes by Norman Redlich, Professor of Law, N. Y. U., Little, Brown \& Co., Boston, 1966.

3 Véase Robert S. Hartman, La estructura del valor: Fundamentos de la axiologia cien. tifica, Publicaciones de Diánoia, Fondo de Cultura Económica, México, 1959; El conocimiento del bien, Publicaciones de Diánoia, Fondo de Cultura Económica, México, 1965.

4 Véase Edmond Cahn, ob. cit. 
universal es una especie de diversión intelectiva de gabinete, pero no una tesis de la que pueden en manera alguna sentirse auténticamente persuadidos.

Repito: en los juicios estimativos hay muchos ingredientes de relatividad o de relacionalidad. Pero esa relatividad o relacionalidad no afecta a los supremos criterios axiológicos.

Por eso, es peligroso el vocablo relativismo. Porque "relativismo" es expresar correctamente dependencias relacionadas. Pero "relativismo" puede también expresar relativismo universal, el cual propiamente es integral subjetivismo, equivalente a pleno escepticismo axiológico.

Reconozco que puede haber como límite a lo que estoy diciendo un caso extremo: el caso de quien considere que la existencia del hombre, que la vida humana en todas sus dimensiones y en todos sus aspectos, constituyen un mal radical y plenario; y que, por consiguiente, todo cuanto tienda a la destrucción y al aniquilamiento de la vida humana debe darse por bienvenido y ser valorado de una manera positiva. Frente a quien "sienta" de tal manera, no hay argumento que pueda ser terminante. Pero lo cierto es que los sedicentes "relativistas integrales" no "sienten" de esa manera, y por lo tanto encarnan una flagrante contradicción. Contradicción que resulta flagrante en grado superlativo, precisamente en aquellos que quieren hacer gala de un extremo rigor lógico.

\section{Diversas presentaciones del escepticismo axiológico, especialmente en ma-} teria juridica

La negación de la estimativa jurídica se ha presentado de diversas maneras en la historia del pensamiento. De modo extremoso, en el escepticismo radical de Pirrón, en el nihilismo máximo de Trasímaco, y en algunos autores de las escuelas escandinavas contemporáneas,,$^{5}$ como por ejemplo, Lundstedt, Olivecrona y Ross, sobre todo en este último. También en el positivismo francés estricto y ortodoxo de Littré y Levy-Bruhl.

El monismo economicista de Marx lleva a la supresión de toda estimativa jurídica, en tanto que interpneta el cambio histórico del Derecho como forzoso efecto de las transformaciones dialécticas de la estructura económica de la sociedad. ${ }^{6}$ A pesar de esto y contradiciéndose, el hombre Marx profesaba una estimativa.

También entraña escepticismo axiológico el materialismo tradicional que tuvo alguna reviviscencia intrascendente en el siglo $\mathrm{xIx}$, $\mathrm{y}$ el evolucionismo total. 7

5 Véase Luis Recaséns Siches, Panorama del pensamiento juridico en el siglo XX, Editorial Porrúa, México, 1963 , primer tomo, pp. 303-320.

6 Véase Luis Recaséns Siches, Tratado general de filosofia del derecho, pp. 449-453.

7 Ob. cit., pp. $448 \cdot 449$. 
Hay otras modalidades de negación de la axiología que se presentan, en apariencia, en forma más moderada, pero que en el fondo son "subjetivismo" o "psicologismo" y, por lo tanto, posturas escépticas, a pesar de que no quieran ser tales.

Algunos de esos subjetivistas no niegan terminantemente los problemas de la valoración. Por el contrario, ellos reconocen la presencia e incluso la inevitabilidad de una estimativa o axiología; pero consideran que la elección de los valores considerados como supremos, $y$, consiguientemente, de los fines tenidos como últimos, constituye un problema que no puede ser resuelto ni por medio de la ciencia, ni tampoco por medio de la filosofía, un problema que no puede ser solventado por razones intrínsecamente válidas, ni objetivamente fundadas. Se trataría de una decisión primaria de carácter subjetivo, de una especie de confesión personal, de la expresión de un modo radical de sentir, que no puede ser justificado mediante razonamientos, ni mediante conocimientos que posean una validez patente o fundable.

Muy típicos ejemplos de esa modalidad de subjetivismo son: el pensamiento de la primera época de Radbruch; ${ }^{8}$ y los ensayos de Kelsen ${ }^{9}$ sobre la justicia.

También hay que mencionar el llamado positivismo o empirismo lógico, filosofía analítica o filosofía lingüística (Carnap, Mach, Schlick, Richard von Mises, Neurath, Reichenbach, Ayer, Stevenson, Ramsey, Ryle, Wittgenstein, Waismann y muchos otros).10 Esa filosofía desenvuelve unas tesis las cuales en el campo de los valores quizá significan muchas veces, en última instancia, el propósito de reducir la axiología --por lo tanto, la estimativa moral y jurídica- a meros análisis psicológicos -o también sociológicos-. Esa filosofía lingüística, llamada también analítica, a menudo -aunque no siempre- suele llegar a la conclusión de que propiamente no puede haber ciencias normativas, ciencias suministradoras de normas ideales ni de valores justificables objetivamente, filosofía que determine lo que es bueno y lo que es justo. Aunque son muchos los méritos de esa filosofía en cuanto a haber esclarecido, a través de finos y agudos anảlisis semánticos, no pocos puntos de gran interés, llega las más de las veces a concepciones subjetivistas en materia de estimativa, la cual frecuentemente reduce a análisis psicológicos o sociológicos. Cierto que algunos de esos filósofos desenvuelven lo que llaman una meta-ética. Pero con su meta-ética no tratan de buscar los principios de la moralidad y de la justicia, sino que lo que desean es describir la índole de la experiencia moral, realizar un análisis descriptivo de los fenómenos morales que sea válido para cualquier experiencia moral:

8 Véase Luis Recaséns Siches, Panorama del pensamiento juridico en el siglo $\mathrm{XX}$, primer tomo, pp. 228-240.

9 Ob. cit., pp. 189-193, 213-220.

10 Véase Giuseppe Lumia, Empirismo lógico e positivismo giuridico, Giuffré, Milano, 1963. 
Varios positivistas lógicos consideran que las expresiones estimativas y normativas no pueden ser verdaderas ni falsas, porque, aunque sean emitidas bajo la forma gramatical de proposiciones, sus predicados no designan datos sensoriales, ni presentes, ni pasados, ni previsibles para el futuro, y, por lo tanto, no pueden ser comprobados. Sin embargo, algunos, como por ejemplo Schlick, aunque restringe el conocimiento en el sentido estricto de esta palabra a las llamadas proposiciones enunciativas o también cognitivas, admiten, no obstante, otra fuente de conocimientos, la "vivencia" o "experiencia inmediata" (Erlebnis). Esta diferenciación, y el tomar en cuenta tal experiencia como algo fundado - si bien no en razones científicas, comprobables por la experiencia sensorial-, implica, por lo menos a mi modo de ver, ya algún abandono de la unilateralidad de otros empiristas o positivistas lógicos.

Pero no todos los cultivadores de la filosofía analítica o empirismo lógico se dejan arrastrar hacia un radical subjetivismo axiológico equivalente a una total postura escéptica en materia de estimativa ética. Por el contrario, algunos eminentes filósofos que trabajan en esta dirección admiten como inevitables los razonamientos axiológicos, así como también aquellos en los cuales se manifiesta una concepción del mundo, aunque con algunas limitaciones. Así, Fernando Salmerón 11 relaciona esos razonamientos con las "actitudes" de las cuales hace un fino análisis. $\mathrm{Y}$, aun cuando considera que en este campo no todo puede pretender una validez objetiva, sin embargo reconoce que hay componentes, relaciones y consecuencias de las actitudes que pueden ser justificados. "Si las actitudes fuesen irracionalidad pura no habría que plantear el problema de su justificación" - y Salmerón plantea ese problema. "La más elemental experiencia de la vida moral nos enseña que un subjetivismo pleno es inadmisible y que, al menos sobre ciertos aspectos, es posible la discusión, el recurso a la información científica y al argumento." "Aunque una actitud no pueda ser refutada ni justificada de manera completa, la investigación empírica y el análisis filosófico pueden poner en claro muchas cosas en torno a ella." De las razones en favor y en contra de las actitudes, ningún principio último puede ser probado con todo rigor; "pero al menos una actitud puede escapar a la crítica si muestra la eficacia de su función social, su coherencia lógica y su compatibilidad con los enunciados de la ciencia", y de esta manera se presenta como más justificada que otros principios. Además en las actitudes hay fuentes y componentes de índole cognoscitiva, junto a otros ingredientes de diversas naturalezas.

"La función crítica de la filosofía - dice Salmerón- no pretende empobrecer el escenario de los ideales humanos y de los modelos personales

11 Véase Fernando Salmerón, "La filosofia y las actitudes morales", Did́noia: Anuario de Filosofía, Fondo de Cultura Económica, Universidad Nacional Autónoma de México, 1969 , pp. 236 ss. 
de virtud moral — del que todos somos cautivos en mayor o menor gradoentre otras razones porque su conocimiento de la variedad de las fuentes de la actitud y de la complejidad de la experiencia moral, le impiden dar por supuesto que todas las cuestiones relacionadas con los principios últimos de la moralidad puedan tener una solución cognoscitiva." Pero, así concluye Salmerón, "precisamente porque la filosofía hace posible un número mayor de decisiones guiadas por el conocimiento contribuye como ninguna otra actividad al progreso moral".

3. Cuál es la cuestión aqui analizada: razón y valores

La cuestión aquí analizada es la siguiente: la de averiguar si en Derecho, -las valoraciones básicas, las radicales, las primeras fuentes de inspiración axiológica, son nada más que mera expresión de un modo subjetivo de sentir o de opinar o si, por el contrario, tienen una validez objetiva y justificada. Y el mismo problema se refiere también a si los últimos fines que un orden jurídico se proponga, fines apoyados sobre valoraciones básicas, son tan sólo la expresión de meras preferencias subjetivas o tienen, por el contrario, una legitimación objetiva.

Adviértase bien que no se trata aquí de todas las valoraciones implicadas por un orden jurídico, ni se trata tampoco de todos los fines que las variadísimas normas jurídicas intenten realizar. La controversia entre subjetivismo y objetivismo afecta sólo a los valores básicos, cimentadores y a los fines últimos; pero no concierne a una serie muy variada de valoraciones y finalidades intermedias en el mundo de lo jurídico.

Supuesto el reconocimiento que se haga de un valor, incluso si ese reconocimiento fuese meramente subjetivo, la corrección de las finalidades inspiradas en dicho valor puede ser enjuiciada desde el punto de vista de la razón, así como puede ser enjuiciada científicamente desde el ángulo sociológico en lo que concierna a la representación de los hechos sociales que tenga quien formule la finalidad o el propósito. $\mathrm{Y}$ estos dos enjuiciamientos pueden y deben desenvolverse sobre la base de análisis científicos.

Asímismo, las cuestiones sobre la congruencia y eficacia de los medios elegidos para la consecución del fin propuesto pueden y deben ser tratadas también científicamente.

Caben análisis científicos críticos sobre la conveniencia o adecuación de Ios medios para lograr el fin propuesto, tema que incluye el examen sobre la posibilidad, la probabilidad, la improbabilidad o la imposibilidad de conseguir el propósito valiéndose de determinados medios a mano. También, la pregunta sobre si hay otros medios; por cuya virtud se pueda alcanzar el propósito más rápidamente, de un modo más completo, y a un costo menor, o sin sacrificio de otros propósitos en conflicto. 
Se puede analizar científicamente también cuáles sean los efectos y los riesgos previsibles en la aplicación de los medios a mano, u otros alternativos, con especial consideración a los propósitos en conflicto, perseguidos por el mismo legislador o por el mismo gobierno, o por la misma comunidad.

Así pues, todos estos análisis y otros similares no son afectados en su validez cientifica por ninguna postura subjetivista. Lo que el subjetivismo científico sostiene es que resulta imposible establecer científicamente cuáles sean los últimos fines valiosos.

Después de las precedentes aclaraciones, resulta patente e innegable que en el Derecho hallamos componentes de razón; por lo tanto, componentes con validez objetiva, sobre todo, como resultado del principio de "razón suficiente". Esto no lo niega ni podría negarlo ningún subjetivista.

Lo que las varias formas de subjetivismo niegan es que los primeros cimientos de un orden jurídico, así como de una estimativa jurídica, es decir, los valores básicos, tengan una validez objetiva y necesaria. Por ende, la controversia entre el subjetivismo o psicologismo, por una parte, y por otra, el objetivismo, se centra alrededor de las valoraciones básicas y de los fines últimos. Pero independientemente de esas valoraciones fundamentales y de las últimas metas, resulta que, en todo caso, es muy extensa en lo jurídico la zona de objetividades de razón. Y muchas de esas objetividades, muchos de esos sentidos objetivos, son importantes componentes de lo que no pocos iusfilósofos contemporáneos llaman "naturaleza de las cosas y de los hechos". ${ }^{12}$

\section{Algunas objeciones criticas frente al neo-positivismo}

Reconozco que el llamado neo-positivismo o empirismo lógico, a través de sus análisis semánticos ha ilustrado y esclarecido muchos temas de gran interés. Además, reconozco también que esa dirección del empirismo lógico puede ofrecer, y de hecho ofrece, no pocas veces un importante método auxiliar para el estudio de importantes temas. Es decir, reconozco logros muy positivos en el estudio de varios asuntos, conseguidos mediante los métodos del empirismo lógico. Pero media una enorme distancia entre tales reconocimientos, por una parte, $y$, por otra, la pretensión de algunos cultivadores del positivismo lógico de presentarse como la última palabra en el campo de la filosofía, como la palabra definitiva, más allá de la cual no puede darse sino una vana ensoñación; de una última palabra de la filosofia, privada ésta de un propio objeto específico y de una propia esfera autónoma, reducida a una mera metodologia de la ciencia. Todo lo que caiga más allá del campo que algunos positivistas lógicos creen dominar, es tachado como carente de sentido; es relegado al reino de lo irracional, de lo arbitrario, de lo pura-

12 Véase Luis Recaséns Siches, Experiencia juridica, naturaleza de la cosa y lógica razonable, Publicaciones de Diánoia, Fondo de Cultura Económica, México, 1971. 
mente emotivo. Ahora bien, todo eso que queda desahuciado comprende nada menos que el mundo de los valores, el cual, por otra parte, sirve para calibrar y justificar las diversas formas de experiencia humana -entre ellas, también las que son tomadas como base por el positivismo lógico para la legitimación de sus tesis. $Y$ así sucede que nada menos que el mundo de la estimativa, que constituye una de las funciones esenciales e inesquivables de la humana existencia, queda relegado al turbio subsuelo pasional, en el cual se considera que no hay ni una sola luz de verdad y que no hay fuente ninguna de conocimiento válido, antes bien tan sólo unos asertos carentes de todo sentido. ${ }^{13}$

Antes de seguir adelante con este análisis crítico, paréceme oportuno recordar otra vez al lector que, si bien suele hablarse en términos generales de "positivismo o empirismo lógico", sin embargo bajo esa denominación se catalogan concepciones muy diferentes de teoría del conocimiento.

Así, según los pensadores del llamado Círculo de Viena (Mach, Schlick, Carnap, etc.), y también la logística de Russell, la validez de una proposición consiste en su verificabilidad empírica. Pero, en cambio, de acuerdo con Neurath, tal validez se hace consistir en el criterio de coherencia lógica del contexto del discurso científico. Según la escuela norteamericana de Morris, el criterio de validez de un conocimiento recibe un matiz pragmatista, porque se le hace consistir en la "operatividad", esto es, en la capacidad de provocar en el oyente respuestas de cierto tipo. Adviértase que Carnap ha pasado por las tres fases, desembocando al menos parcialmente, en una postura parecida a la de Wittgenstein. Recordemos además que Wittgenstein, aunque con muchas dimensiones profundamente originales, representó una postura cercana a la del Círculo de Viena, y bajo alguna influencia de Russell; y posteriormente dio nuevos giros a su pensamiento. Si bien con características personales propias, cada uno de ellos, Reichenbach, Kempel y Tarski confluyen hacia una dirección parecida, lo cual puede decirse también de la escuela de los analistas ingleses de Oxford, si bien el pensamiento de Ayer haya tenido una ulterior evolución.

He traído al recuerdo esas variedades dentro de las diferentes epistemologías del positivismo o empirismo lógico, con el propósito de llamar la atención hacia el hecho de que dicho positivismo está muy lejos de poseer una clara, unitaria o inequívoca teoría del conocimiento. Por tanto, las cosas no son tan sencillas como algunos empiristas lógicos querrían hacerlo creer.

Repito que debemos estimar el propósito de rigor mental que inspira a los pensadores del positivismo o empirismo lógico, y las muchas muestras de fina capacidad de análisis que han dado. Así como merece también aplauso su propósito de barrer los problemas mal planteados, las soluciones puramente

13 Véase Giuseppe Lumia, ob. cit., pp. $96 s s$. 
verbales, la lírica conceptual, la verbosidad y las proyecciones de las querencias meramente personales.

Sin embargo esos méritos no son capaces para justificar la arbitraria supresión de todos los temas auténticamente filosóficos, de los temas de fondo, que han constituido siempre la preocupación de la filosofía desde los presocráticos hasta el presente.

Ese neo-positivismo cree poder encontrar la solución de los problemas de la filosofía mediante la disolución de la filosofía en el análisis del lenguaje. Pero haciendo tal cosa incurre en un curioso paralogismo, que consiste en que aquello que es tan sólo un instrumento al servicio de la filosofía, queda convertido en la filosofía misma, con el resultado melancólico de desembocar en un mero ejercicio erudito. Y así queda evaporada la auténtica filosofía.

Filosofía es la consideración, la reflexión, el propósito de aclaración, hasta donde sea posible, de los problemas que inevitablemente, insoslayablemente, nos plantea nuestra existencia humana. $\mathrm{Y}$ entre esos problemas nos encontramos nada menos que con toda la temática de la valoración.

El filósofo no es libre de escoger caprichosamente los temas que más le agraden. Por el contrario debe partir de los problemas que la humana experiencia le plantea. Esos problemas son "datos" no puestos ni inventados por el filósofo. Por el contrario, el filósofo tropieza, quiéralo o no, debe tropezar, si es que no cierra sus ojos, con tales cuestiones. $Y$ no es lícito decretar de un plumazo radicalmente que tales cuestiones no tienen sentido, puesto que con ello lo que se hace es, en fin de cuentas, declarar que nada de lo que en la vida se presenta tiene ningún sentido. Y de eso no se salvarían ni siquiera los supuestos fundamentales del empirismo lógico.

No me propongo aquí, ni remotamente, hacer un análisis crítico del neopositivismo y de su epistemología. Quiero tan sólo someter a crítica su nihilismo axiológico, representado por varios de los miembros de esas escuelas, no por todos, pero sí por algunos de los más conocidos, como Ross en el campo del pensamiento jurídico.

Lo que me parece necesario criticar es la amputación tremenda que el neo-positivismo hace en el campo de la filosofía, expulsando de la misma el propósito de una interpretación satisfactoria del mundo de los valores y del mundo histórico. Algunos neopositivistas suprimen la estimativa o axiología, porque los valores no son susceptibles de verificación. Y partiendo del supuesto, puramente arbitrario, de que sólo los enunciados verificables tienen significación, algunos neopositivistas concluyen que los juicios de valor no tienen sentido; y que los valores mismos tienen sus raíces en el subsuelo pasional del hombre y que, por lo tanto, caen fuera de todo estudio por la razón.

Otra vez se vuelve a caer en el craso error de identificar la razón con 
la lógica físico-matemática. Esa lógica físico-matemática es la perteneciente al intelecto formal, la cual desde luego presta grandes servicios en el campo de la matemática y de la física, pero de ninguna manera agota todas las posibilidades de la razón. Una vez más quiero referirme a lo manifestado por Ortega y Gasset sobre este tema. "Todas las definiciones de la razón que hacían consistir lo esencial de ésta en ciertos modos particulares de operar con el intelecto, además de ser estrechas, la han esterilizado, amputándole y embotando su dimensión decisiva. Para mí es razón, en el auténtico y rigoroso sentido, toda acción espiritual que nos pone en contacto con la realidad, por medio de la cual topamos con lo trascendente. Lo demás no es sino... puro intelecto; mero juego casero y sin consecuencias, que primero divierte al hombre, luego lo estraga, y, por fin, le desespera y le hace despreciarse a sí mismo." 14

Los juicios de valor son inextirpables en la existencia humana y en todas y cada una de las funciones de ésta. Inextirpables incluso en la función del conocimiento empírico verificable. En efecto, incluso la actitud que el científico empírico asume ante el objeto de su investigación implica una toma de actitud axiológica frente a ese objeto y frente al modo de investigarlo. $Y$ si el científico no está en condiciones de justificar esa su actitud ante el objeto de su estudio y el modo según el cual lo estudia, toda la supuesta validez de su ciencia se derrumba. Y no se replique a esto diciendo que la actitud del científico debe ser imparcial. De acuerdo. Pero esa actitud de imparcialidad constituye ya una toma de posición axiológica. La supuesta neutralidad axiológica de la ciencia es siempre relativa; pues expresa la indiferencia respecto de determinados valores, por ejemplo, de los éticos o estéticos, pero no una indiferencia plenaria respecto de todos los valores. Aparte del interés práctico que mueva a la investigación científica, la actitud del hombre de ciencia no es nunca una postura de indiferencia, sino que, por lo menos, lo es de curiosidad y de interés intelectual hacia el objeto de su investigación. Incluso la elección que el cientifico hace de los materiales sobre los cuales desenvuelve su investigación implica un juicio de valor. ${ }^{15}$

No se puede eliminar del contenido de la filosofía un intento de interpretación del mundo de los valores en tanto que valores. Pues claro que no puede considerarse como interpretación de los valores el aserto de Ross de que nuestras valoraciones éticas son tan sólo el resultado de las secreciones de las glándulas suprarrenales.

No hay ningún fundamento para reducir el empleo de la razón al campo de la experiencia sensible, renunciando a toda indagación sobre el mundo de los valores.

14 Véase José Ortega y Gasset, Obras completas, Revista de Occidente, Madrid, 1947, tomo VI, p. $4^{6}$.

15 Véase Giuseppe Lumia, ob. cit., pp. 100-102. 
Incidentalmente recordemos un punto, que los positivistas suelen olvidar muchas veces: que la validez de las reglas lógicas y matemáticas no se apoya sobre ningún dato experimentable. De modo que toda la epistemología de la física elaborada por algunos neopositivistas queda flotando en el vacio sin ningún punto de apoyo positivista.

Repito que Ia razón no puede limitarse a suministrar los instrumentos lógicos para la investigación de la ciencia física. La razón se plantea, quiérase o no, el problema del Universo en tanto que Universo, y sobre todo la cuestión del lugar que en éste ocupa el hombre.

El problema que Kant expresaba en la pregunta "¿qué puedo esperar?" es un problema que no puede ser eludido por el hombre, en tanto que vive y tiene conciencia de su vivir; y cuando se cree haberlo eliminado, declarándolo "carente de sentido", en realidad con ello se da ya una respuesta, aunque sea una respuesta negativa. ${ }^{16}$

Advierta el lector que digo que el hombre no puede eludir el planteamiento de ese problema metafísico. Con esto no afirmo que la respuesta a dicha interrogación pueda adquirir una evidencia irrefragable, un carácter apodíctico, sea por intuición directa o inmediata, sea por vía demostrativa. En metafísica se opera en parte sobre la base de intuiciones directas e inmediatas que suministran una patente evidencia objetiva. Éste es el caso de múltiples - no de todas- intuiciones de valores. Es también el caso de conexiones esenciales presentes de manera directa e inmediata en la conciencia. Pero, por otra parte, en los desarrollos de todas las metafísicas lo que encontramos son variados razonamientos de tipo argumentativo, en el sentido de Perelman. El resultado de las argumentaciones no es una verdad patente, evidente, irrefragable, inobjetable, que se imponga forzosamente por si misma sin posibilidad de eludirla. Las argumentaciones suministran razones, más o menos poderosas, más o menos plausibles, que conducen a resultados de probabilidad, los cuales operan a veces con suficiente fuerza persuasiva; pero que no entrañan la necesidad del reconocimiento ineluctable.

En las argumentaciones se procede a formular hipótesis, cuyo contenido no resulta evidente por vía analítica, ni verificable mediante el experimento; pero que pueden ser tomadas como bases razonables de interpretación, aunque desde luego dejando siempre la posibilidad de que los problemas queden abiertos.

Las argumentaciones metafísicas se fundan en razones, pero en razones diferentes de las analíticas, y de las estrictas deducciones racionales. Se fundan más bien en razones "razonables". La filosofía no es ni poesía ni mito, porque se vale de "razones". Pero tampoco es simple matemática ni pura física. Maneja una serie de razones para tratar problemas humanos ineluctables, es decir, cuyo planteamiento y cuyo tratamiento no se puede esquivar.

16 Ob. cit., pp. 106-109. 
Subjetivamente esas razones pueden resultar hipótesis muy persuasivas; pero no pueden alcanzàr un grado de evidencia irrebatible.

El reconocimiento de que los resultados de la reflexión metafísica no adquieran una evidencia apodíctica no significa de ninguna manera la recaída en una posición de subjetivismo o de escepticismo nihilista, según el cual todas las hipótesis metafísicas resulten equivalentes y, por consiguiente, ociosas y desprovistas de cualquier sentido. Nada de eso. En el examen de las diferentes hipótesis metafísicas podemos distinguir grados diversos de atendibilidad, verosimilitud, probabilidad, plausibilidad; diversos grados de capacidad persuasiva. Lumia ${ }^{17}$ dice que esos diversos grados dependen, en primer lugar, en la coherencia de los argumentos aducidos y de la concordancia de éstos con los datos de la experiencia, pues no parece digna de ser tomada en cuenta una filosofía que caiga en contradicción con la lógica o con la experiencia. En segundo lugar, para las hipótesis metafísicas hay una especie de verificación indirecta, una verificación sui generis, que les confiere, si es que no la certeza objetiva, por lo menos un cierto grado de convencimiento: tal verificación está constituida por la mayor o menor capacidad de una hipótesis para suministrar una explicación integrada de la experiencia, en todas las múltiples formas en las cuales la experiencia se presenta. El ser del hombre no se agota en la función cognoscitiva, sino que se desarrolla y desenvuelve en otras direcciones no menos importantes, cuales son las de la voluntad, el sentimiento, el gusto. "Una hipótesis metafísica es tanto más atendible, cuanto consigue de mejor manera dar cuenta de toda esa gama de experiencias que no pueden reducirse - sin amputar de ellas cuanto en las mismas hay de más vivo-, al mero hecho de conocer; y tanto más atendible, cuanto consigue hacer comprensibles del mejor modo las relaciones entre el mundo de la realidad y el mundo de los valores. En este sentido, no se puede decir que la metafísica carezca de una propia experiencia: la experiencia de la metafísica y la vida moral, entendiendo con esta expresión la conciencia misma del hombre, en tanto que centro en el cual se reduce a unidad la multiplicidad de sus experiencias." 18 Una metafíscia aparecerá tanto más válida, cuanto sea más capaz de conferir coherencia a la multiplicidad de las actitudes que constituyen las manifestaciones de nuestra personalidad; cuanto mejor consiga introducir una mayor riqueza de motivos en nuestra vida individual y social; cuanto sepa dar mejor una más cumplida justificación de nuestra presencia en el mundo; cuanto mejor resulte capaz de ofrecernos más vastos horizontes humanos y los medios para la comprensión y dominación de esos horizontes. ${ }^{19}$

Pero el tema del presente estudio no es principalmente el de la reivindi- 
cación de la metafísica como un conato de conocimiento inevitable, sino que es la cuestión concerniente a la raíz objetiva de la estimativa jurídica.

Adviértase que repito insistentemente la referencia a la primera raíz o primer fundamento de la estimativa jurídica. Pues, según ya he expuesto, los juicios de valor proferidos por la estimativa jurídica contienen ingredientes empíricos, a saber, contienen referencias a situaciones particulares de hecho; por lo tanto, la estimativa está condicionada históricamente. Ya hice enérgico hincapié en que las "relacionabilidades" de los juicios de valor no implican en manera alguna subjetivismo. Si se prefiere llamar relatividades a esas "relacionabilidades", no hay inconveniente, siempre y cuando no se equipare la dimensión de relatividad (relatividad a ciertos supuestos de hecho) con una postura de subjetivismo escéptico.

Conviene plantear este tema en los términos más rigorosos.

Según el frenéticamente extremoso neopositivismo de Ross, las palabras justo e injusto carecen de todo sentido estimativo; pues representan tan sólo la designación de la conducta de una persona provista de poder para imponer sus decisiones y, en fin de cuentas, el resultado de la secreción de las glándulas suprarrenales.

Por de pronto, adviértase que esa peregrina tesis contradice diametralmente el modo de pensar y de sentir constante de los humanos a través de la historia, de los filósofos que han meditado sobre estos problemas y de las gentes del pueblo que muchas veces han ofrendado su vida al servicio de lo que consideraron una causa de justicia. Claro que podría contestarse esta objeción diciendo que los hombres han vivido siempre en un perenne autoengaño. Pero tal aserto tendría unas dimensiones de enormidad, que para ser admitido necesitaría de una explicación, suficiente, que nos diera cuenta del por qué los hombres habrían vivido y tendrían forzosamente que vivir en ese autoengaño. Y esto no lo ha contestado ni Ross, ni ningún positivista, ni ningún neopositivista.

En segundo lugar, si uno puede aducir numerosos ejemplos de esti. maciones jurídicas cuya validez se presenta con los caracteres de apodíctica evidencia, de ineludible necesidad, de manera patente, por virtud de una intuición de algo dado en presencia inmediata, entonces, se derrumba estrepitosamente el total escepticismo axiológico de los positivistas y neopositivistas.

La evidencia incontrovertible de algunos juicios axiológicos resalta mejor cuando se los expresa en forma negativa, esto es, cuando se presentan ejemplos de flagrante o indubitable injusticia. He aquí algunos ejemplos de juicios necesaria y totalmente injustos. "El juez venal debe ser premiado; mien. tras que el juez imparcial debe ser castigado." "El Estado debe convertir en esclavos, en meras cosas, a los trabajadores y tratarlos como tales siervos." "Se debe implantar un sistema fiscal que grave con impuestos del $50 \%$ los salarios menores de mil pesos; y que grave con impuestos tan sólo del $5 \%$ 
los ingresos superiores a diez mil pesos." "Infracciones iguales deben ser sancionadas de modo diferente, de manera más o menos grave, según que el infractor resulte antipático o simpático al juzgador." "El fraude debe ser premiado; $y$, en cambio, la buena fe debe ser castigada." "Deben ser punibles todos los movimientos en pro de la independencia nacional." "Para estimular la productividad de los picapedreros se debe emplear el látigo que los induzca a una mayor dosis de trabajo eficaz." "Se debe asesinar a todo aquel que constituye un obstáculo o una dificultad en la realización de los propios planes de uno." "El monto del salario deberá ser inverso a la cantidad de trabajo producido." "Se declara libre la violación de mujeres, de acuerdo con la fuerza física de cada varón."

Según Ross y otros neopositivistas, la tacha de injusticia flagrante y total que se profiere sobre los anteriores juicios es tan sólo el resultado de unas secreciones de determinadas glándulas endocrinas. ${ }^{20}$.

Dicho sea con todo respeto, entiendo que no vale la pena perder el tiempo en refutar disparate de tan ilimitado tamaño. Baste con decir que, frente a la caprichosa pedantería cientifista de Ross, nos encontramos con el hecho indestructible de una conciencia evidente y autojustificada de modo objetivo, que repudia todos los juicios anteriores como plenarias injusticias, y que sostiene que lo justo es precisamente lo opuesto a cada uno de esos juicios.

Claro que he presentado esta confrontación en la forma más extremista, para sacar de la misma el resultado de irrefragable evidencia. Pero, en fin de cuentas, el mismo repudio merece la tesis presentada en forma aparentemente menos brutal, de que en axiología todo depende del medio ambiente social histórico en que uno se ha educado. Repito una vez más que reconozco el condicionamiento social-histórico de muchos componentes de los juicios estimativos. Pero excluyo de tal condicionamiento el primer cimiento o la primera raíz de los juicios estimativos. Resultaría vanamente presuntuosa y ridículamente ingenua la pretensión de que aquello que consideramos como esquema de Derecho justo en nuestros países occidentales tuviese que ser aceptado sin modificaciones por pueblos de un círculo cultural diferente. Pero resultaría también indebido, basándose en la hipótesis del total condicionamiento histórico social de tales juicios, afirmar que cuando uno ha nacido occidental necesita que se le reconozca la libertad individual; pero que si uno ha tenido la desgracia de nacer ruso o chino entonces no debe disfrutar de ninguna libertad individual. Debajo de todas las múltiples diversificaciones histórico-culturales, debemos reconocer un fondo humano común. Lo contrario nos llevaría a una tesis parecida a la de la antropología nazi, según la cual todas las gentes no germánicas deberían ser consideradas pura y exclusivamente como simples animales.

20 Véase Alf Ross, On Law and Justice, p. 275. 
Hay razones suficientes para demostrar que la raiz primera o el cimiento primero de la estimativa constituye un apriori objetivo. ${ }^{21} \mathrm{He}$ expuesto esas razones suficientes en otras obras mías. Pero aparte de tales razones decisivas, lo que acabo de presentar ante la atención del lector hace patente que nos encontramos con juicios de valor cuya justificación aparece como evidente a primera vista, como proposiciones apodícticas cuya validez resulta irrecusable, porque constituye un dato directo e inmediato de la conciencia. Esto no representa de ninguna manera el aserto de que el contenido pleno o íntegro de todos los juicios de valor sea un apriori objetivo. Ya indiqué que muchos juicios de valor albergan componentes que se refieren a hechos humanos sociales contingentes y empíricos, los cuales condicionan esos juicios a circunstancias determinadas: precisamente esos juicios son relativos a las circunstancias que toman en cuenta. Pero el mero hecho de que encontremos muchos juicios estimativos con evidente validez apriorística, con dimensión apodíctica irrecusable, basta para hacer naufragar la tesis del subjetivismo, es decir, para demoler el omniescepticismo axiológico.

Así lo reconocen iusfilósofos que han tenido serios contactos con el neopositivismo, como, por ejemplo Bobbio, ${ }^{22}$ quien justifica la investigación filosófica de los valores jurídicos, por lo menos dentro de un campo limitado, pero firme. Así también, aunque con nuevos fundamentos diferentes, Robilant. ${ }^{23}$

Reconozcamos además que el condicionamiento histórico-cultural de las valoraciones no justifica el subjetivismo ético. El hecho de que muchas valoraciones se refieran a determinadas realidades concretas, de que sean relativas a esas realidades, no significa lógicamente que tales valoraciones sean exclusivamente subjetivas. El hecho de la relatividad histórica de las valoraciones no implica el subjetivismo de los valores. Por el contrario, la experiencia misma muestra cómo, a pesar de tanta variedad y diversidad de opiniones, se manifiesta un consenso general sobre determinados valores básicos, una especie de opinión común en la que participan diversos individuos que, sin embargo, están sometidos a un condicionamiento cultural diferente. Y en todo caso, frente a los subjetivistas o escépticos en materia axiológica queda siempre en pie el argumento de la "réductio ad Hitlerum". Clạro que sería erróneo atribuir a la "reductio ad Hitlerum" el mismo valor demostrativo que en lógica se atribuye a la reducción al absurdo; pero es innegable

27 Véase Luis Recaséns Siches, Introducción al estudio del derecho, Edit. Porrúa, México, 1970, pp. 283-289; Tratado general de filosofia del derecho, $4^{\text {a }}$ ed., Edit. Porrúa, México, 1970, pp. 400-405; 406-420.

22 Véase Norberto Bobbio, Lezioni de Filosofia del Diritto, Torino, 1945, caps. II, III, IV y V; Introduzione alla Filosofia del Diritto, Torino, 1948, pp. 46ss., 176; "La nozione di Giustizia", Archivio Giuridico, 6 serie, vol. XI, 1952, Pp. 16-33.

23 Véase Enrico Di Robilant, Sui Principi di Giustizia, Milano, 1951, caps. I, II, IV, V y VI. 
el gran peso persuasivo, o mejor dicho disuasivo, que surge de tal argumento. Los subjetivistas en materia axiológica carecen en absoluto de toda base para protestar contra las atrocidades y los crímenes cometidos por el régimen nazi.

\section{El positivismo juridico fomenta la conformidad con todas las atrocidades}

Se ha repetido muchas veces, con sobrada razón, que el positivismo jurídico fomenta la actitud de aceptar y obedecer todos los mandatos de quienes disponen de la fuerza: de admitir y cumplir todos los imperativos emanados de la fuente oficial a través de las formas habituales para los pronunciamientos políticos. El positivismo jurídico acepta como buenos todos los imperativos emanados de quienes ejercen el poder, sin requerir que tales imperativos concuerden, al menos en una gran proporción, con criterios axiológicos, tanto en lo que se refiere al contenido de tales mandatos, como en cuanto a los métodos de su elaboración. El positivismo jurídico anima una lealtad ciega a cualquier cosa que se produzca bajo la aparente etiqueta meramente superficial de Derecho.

El positivismo jurídico aceptó la cadena de causalidad psicológica que fue habitual en la Alemania nazi e incluso en la pre-nazi: un positivismo que preparó la mente de los juristas alemanes a aceptar como Derecho cualquier cosa que se presentase bajo tal nombre, cualquier cosa que fuese impresa oficialmente por el gobierno, cualquier cosa que procediese de "arriba hacia abajo".

No olvidemos que el postulado fundamental del positivismo, lo mismo que del subjetivismo, implica la negación de todo fundamento ético para el Derecho. Ahora bien, si no existe ningún fundamento ético para el Derecho, entonces no tiene sentido en absoluto hablar de una obligación moral de cumplir las normas jurídicas. Cierto que tal consecuencia es aceptada por muchos de los iusfilósofos de las escuelas escandinavas contemporáneas. Pero, independientemente de la hombría de bien de tales iusfilósofos, independientemente de su radical honradez, hay que reconocer que ellos identifican en última instancia el Derecho con la fuerza bruta, o con los resortes psicológicos elaborados astutamente por esa fuerza bruta.

Sucede paradójicamente en nuestro tiempo que en antítesis con los nuevos desenvolvimientos subjetivistas, ha crecido y crece cada día más la preocupación por la justicia. Esta preocupación alcanza con inigualado dramatismo, una preminencia práctica en la realidad de los asuntos humanos de todos los días. En efecto, contemplamos en esta etapa histórica un torrente de declaraciones, manifiestos, coléricas demandas, petición de solemnes garantias, normas e instituciones al servicio de la justicia. Asistimos a enérgicas campañas electorales, a revoluciones y guerras sangrientas que apelan a la justicia. Presenciamos el establecimiento de organizaciones y tribunales in- 
ternacionales al servicio de ideales de justicia. En suma: gritos irreprimibles -de dimensiones mundiales - en favor de la justicia individual, social e internacional. Justicia reclamada, propugnada y, a veces, conseguida, en pro de las mujeres y de los niños, de las minorías religiosas y étnicas y de los sindicatos obreros, de los esclavos (como los que hay en la Unión Soviética, en la Unión de Sudáfrica y en algunos países árabes) y de los siervos y de los peones que todavía persisten en algunos países iberoamericanos, de los obreros desocupados, de los apátridas, de las madres solteras y de los hijos ilegitimos, de los inválidos, de los enfermos, de los indigentes, de las marginadas masas en subdesarrollo que gimen en la miseria, en la ignorancia y en la enfermedad.

En los países libres, de civilización occidental, los mejores abogados en sus alegatos inyectan consideraciones de justicia y no sólo tecnicismos legalistas; los mejores jueces tratan de mostrar que sus sentencia no sólo se apoyan en las reglas establecidas sino también sobre bases de justicia; y los funcionarios administrativos más competentes se esfuerzan por desenvolver su acción de modo equitativo.

No se trata de desconocer que en muchos casos se da una dosis de hipocresía; pero no en todos. Sin embargo, no se olvide que según certeramente expresa el dicho popular "la hipocresía es un homenaje que el vicio rinde a la virtud". Y todavía más, el uso hipócrita de este término viene a dar mayor relieve al hecho de que tienen vigencia social y pública las convicciones de la justicia. Tales convicciones poseen un sentido y un alcance que no es posible hacer a un lado, porque ocupan la preferente atención de una mayoría de la humanidad.

Las observaciones que anteceden no implican el propósito de tomar como criterio de verdad o de rectitud del pensamiento un recuento de opiniones. En materia filosófica y en el campo científico la rectitud de unos asertos no puede ser fundada sobre el sufragio. La democracia es un sistema político que está ciertamente justificado, pero no puede convertirse en pauta de verdad científica ni de rectitud filosófica. Por consiguiente, las consideraciones que he hecho sobre la presencia del tema de la justicia en un sinnúmero de conciencias, en todas las regiones de la tierra, no pretende consiituir un argumento contra el subjetivismo estimativo o axiológico. Se trata de otra cosa muy diferente. Se trata de presentar un hecho de enorme alcance: el hecho de la presencia viva de las preocupaciones por la justicia en un sinnúmero de conciencias individuales, y en un campo extensísimo de hechos colectivos que surgen en todas latitudes y que son fuentes no sólo de preocupación, sino de acción. Es decir, se trata por lo visto de actitudes que constituyen funciones inextirpables de la vida humana. Se trata de problemas que los hombres afrontan, tienen que afrontar, quiéranlo o no. Se trata de datos de gran tamaño en la existencia humana. Y eso no se puede ex- 
pulsar arbitrariamente del horizonte de la vida, como pedantemente lo hacen algunos positivistas, declarando que todo ello constituye tan sólo un conjunto de seudoproblemas.

El filósofo debe desenvolver su meditación y su investigación disfrutando un ámbito de máxima libertad para tratar sus temas del modo que entienda está justificado. Pero, en cambio, su libertad no debe ser máxima en cuanto a la elección de sus temas. Los temas debe tomarlos de los datos de la vida humana, de los datos, los cuales, aunque patentes en tanto que datos, plantean inexcusablemente problemas de interpretación o de aclaración.

Quienes se atreven a declarar que se trata tan sólo de seudoproblemas debieran ser capaces de suministrar la explicación de por qué los seres humanos los sienten como auténticos problemas, que tienen que enfocar y resolver.

No olvidemos que ninguna teoría científica o ninguna concepción filosófica puede jamás alcanzar la inmediatez que tienen los datos directos de la conciencia. Por eso, querer borrar esos datos inmediatos y directos de la conciencia a título de un prejuicio supuestamente científico es un alarde de fanfarronería cientifizante, pero no resultado de genuina ciencia ni de auténtica filosofía.

Lo que acabo de decir no significa que tengamos que admitir irrevocablemente los datos de la conciencia tal y como ellos se nos presentan. Como datos son irrecusables. Pero esos datos irrecusables plantean muchos problemas a la ciencia y a la filosofía, problemas que ambas intentan resolver mediante razonamientos. El resultado de esos razonamientos suministrará una aclaración o una interpretación de los datos. Pero lo que no puede ser el resultado de la ciencia ni de la filosofía es la negación de esos datos, o sea el declararlos simplemente como cosas sin sentido. Lo cual es lo que precisamente hace Ross cuando equipara el vocablo "justicia" como un simple ruido, y añade que "invocar la justicia es lo mismo que golpear una mesa".

Instituto de InVESTIGACIONES FILOSÓFICAS

Luis Recaséns SiGHes Universidad Nacional Autónoma de México 